\title{
Physical, mechanical, thermal and morphological analysis of date palm mat (DPM) and palmyra palm fruit (PPF) fiber reinforced high density polyethylene hybrid composites
}

\author{
Afroza Khatun $\mathrm{M}^{1,2 *}$, Sultana $\mathrm{S}^{3}$, Parvin $\mathrm{Nur}^{3}$ and Sarwaruddin Chowdhury AM${ }^{1}$ \\ ${ }^{1}$ Department of Applied Chemistry and Chemical Engineering, Faculty of Engineering and Technology, University of Dhaka, Dhaka-1000, Bangladesh \\ ${ }^{2}$ Department of Chemical Engineering, Faculty of Engineering, Jashore University of Science and Technology, Jashore, Bangladesh \\ ${ }^{3}$ Bangladesh Council of Scientific and Industrial Research, Dhanmondi, Dhaka-1205, Bangladesh
}

\begin{abstract}
In this work, date palm mat (DPM) and palmyra palm fruit (PPF) fibers were incorporated to high density polyethylene (HDPE) for the fabrication of hybrid composites. The composites were prepared by compression molding at different weight \% (5, 10, 15, 20 and 25 wt \%) of fiber contents. Physical, mechanical and soil degradation properties were studied. Thermal properties, scanning electron microscopy (SEM) and Fourier-transform infrared (FT-IR) analysis of the 100\% HDPE and hybrid composites were also done. The results from experiments indicate that the properties of the hybrid composites at $5 \%$ fiber content are better than $100 \%$ HDPE.
\end{abstract}

\section{Introduction}

Hybrid composite materials are made by combining two or more different types of fibers in single matrix phase or single reinforcing phase with multiple matrix phases or multiple reinforcing and multiple matrix phases. The mechanical properties of hybrid composites depend on the fiber length, fiber orientation, weight fraction of the reinforcement, interaction between fiber and matrix [1]. Polymer composite materials are being used in aerospace, automotive, marine, infrastructure, military, leisure boats, aircraft industry and sport equipment. Present day industry takes an interest in environment friendly polymer composite materials, due to economic and ecological reasons. Natural fibers are renewable and obtained from natural resources possessing several advantages [2]. Natural fiber composites combine plant-derived fibers with a plastic binder. The natural fiber component may be wood, sisal, hemp, coconut, cotton, luffa, flax, jute, abaca, banana leaf fibers, bamboo, wheat straw or other fibrous material [3]. The primary advantages of natural fibers are low density, low cost, biodegradability, acceptable specific properties, less wear during processing and low energy consumption during extracting as well as manufacturing composites and wide varieties of natural fibers are locally available [4]. The most important matters in the development of natural fiber reinforced composites are (i) surface adhesion characteristics of the fibers, (ii) thermal stability of the fibers, and (iii) dispersion of the fibers in the case of thermoplastic composites [5]. The developed composite exhibits superior mechanical properties than the parent constituents [6]. The presence of fiber or other reinforcement in a thermoplastic matrix increases the composite strength. Polyethylene and polypropylene are well suited for use as matrix material. HDPE has very low glass transition temperature associated with a good retention of mechanical properties including flexibility and impact resistance at low temperatures and easily molded [7]. Several studies on the hybrid composites like Jute/sisal and epoxy, bamboo and glass fiber reinforced epoxy, banana/ pineapple and epoxy, banana fiber reinforced polypropylene, Glass-Hemp-Banana Fiber Reinforced Polymer Composites showed better mechanical properties [8-12].

Date palm (Phoenix sylvestris) and Palmyra palm (Borassus flabellifer) trees are plentifully available in Bangladesh. Date Palm mat and Palmyra Palm fruit fibers are considered as an agricultural waste in Bangladesh. It is evident from the literature that no work has been reported on the utilization of date palm mat and Palmyra Palm fruit fibers reinforcement in HDPE hybrid composites fabrication. These new renewable and green source of reinforcement in composite materials which can be cheap and ecological. The aim of this study is to use of the date palm mat and Palmyra Palm fruit fiber as a potential reinforcing material in thermoplastic composite. In this study, date palm mat (DPM) and Palmyra Palm fruit (PPF) fibers reinforced HDPE hybrid composites were prepared. The physical, mechanical, thermal, morphological and degradation properties of the hybrid composites were studied and these new composites may find diversified applications like door panels, seat backs, headliners, package trays, dashboards, and interior parts of automotive [13], furniture, building and construction industries [14] etc.

\section{Experimental procedure}

\section{Materials}

HDPE was purchased from Saudi Polymers Company, Saudi Arabia. HDPE has density $0.946 \mathrm{~g} / \mathrm{cm}^{3}$ and melt index $0.18 \mathrm{~g} / 10 \mathrm{~min}$. HDPE granules were grinded to $200-250 \mu \mathrm{m}$ by a grinding machine for proper mixing between fibers and matrix. Date Palm mat fibers

${ }^{*}$ Correspondence to: Most. Afroza Khatun, Department of Applied Chemistry and Chemical Engineering, Faculty of Engineering and Technology, University of Dhaka, Dhaka-1000, Bangladesh, E-mail: afroza.jstu@gmail.com

Received: July 05, 2019; Accepted: July 15, 2019; Published: July 18, 2019 
Khatun AM (2019) Physical, mechanical, thermal and morphological analysis of date palm mat (DPM) and palmyra palm fruit (PPF) fiber reinforced high density polyethylene hybrid composites

(phoenix Sylvestris) and Palmyra Palm (Borassus flabellifer) fruit fibers were collected from the rural area of Jashore, Bangladesh. The DPM and PPF fibers were cut into 2-3 $\mathrm{mm}$ using hand scissors.

\section{Hybrid composite fabrication}

Composites were prepared by compression moulding technique. DPM and PPF fibers were weighed at a ratio (50:50) and mixed thoroughly. The fibers and HDPE were mixed in a blender according to the Table 1 . The mixture of fiber and HDPE were poured into the mold $\left(12 \times 15 \mathrm{~cm}^{2}\right)$ and finally hot pressed (Paul Ottoo Weber Press Machine) at $160^{\circ} \mathrm{C}$ for 5 minutes between two steel plates under a pressure of 200 $\mathrm{kN}$. At room temperature and under $200 \mathrm{kN}$ pressure the moulds were cooled for 5 minutes and released from the mold. The finished hybrid composite is shown in Figure 1. The composites were cut to prepare specimens according to ASTMD 3039/ D3039(M) (2002) standard method and shown in Figure 1.

\section{Bulk density of composites}

The bulk density of the composites was determined by using the formula.

$D=(($ Weight of the composite $) /($ Length $\times$ Width $\times$ Height $)$ of the composite))

\section{Water absorption test of composites}

Water absorption tests of the composites were performed according to ASTM D570-99. Three replicate samples were employed to water absorption tests and the average results were presented. The percentage increase in weight during immersion was calculated as follows:

Increase in weight, $\%=(($ wet wt-conditioned $\mathrm{wt}) /$ conditioned wt) $\times 100$

\section{Mechanical properties}

Mechanical tests (tensile strength, percent elongation at break, tensile strength at break and yield strength) of the composites were carried out using universal strength tester (model 1410 Titans, capacity $5 \mathrm{kN}$, England). The tests were performed according to ASTM D 3039/D 3039 (M) (2002) standard method with a crosshead speed 10 $\mathrm{mm} / \mathrm{min}$. The average values for five samples were reported.

Table 1. The composition of fibers and HDPE in composite samples

\begin{tabular}{|c|c|c|}
\hline Samples & Fiber Content (wt\%) & HDPE (wt\%) \\
\hline $100 \%$ HDPE & 0 & 100 \\
\hline S1 & 5 & 95 \\
\hline S2 & 10 & 90 \\
\hline S3 & 15 & 85 \\
\hline S4 & 20 & 80 \\
\hline S5 & 25 & 75 \\
\hline
\end{tabular}
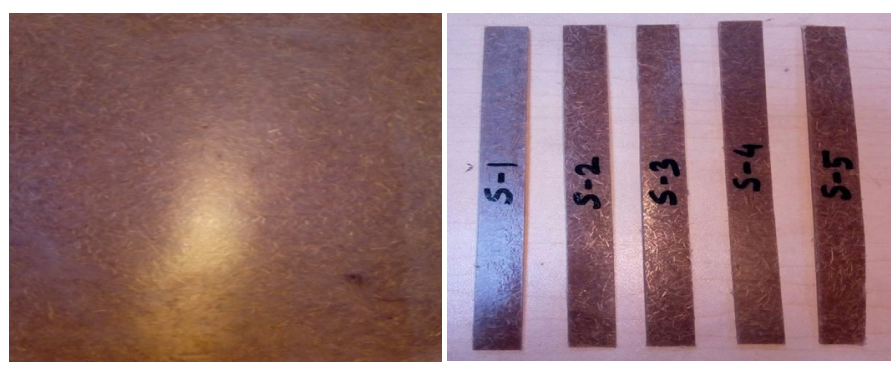

Figure 1. Finished composite sample and specimens for mechanical properties

\section{FTIR spectroscopy}

The FTIR of the composites were carried out by a FT-IR/NIR spectrometer (Frontier, Perkin Elmer, USA). The FTIR spectra were recorded in the 4,000-650 $\mathrm{cm}^{-1}$ region. FT-IR spectroscopy was used for the identification of functional groups of the composite samples.

\section{SEM analysis}

Surface morphology of the composites were examined by a field emission scanning electron microscope (JEOL JSM-7600F). SEM analysis were done on the fracture surfaces of the tensile specimens.

\section{Thermal properties analysis}

A NETZSCH instrument (STA 449 F3, Jupiter) was employed for the thermogravimetric analysis (TGA) and differential scanning calorimetry (DSC) analysis of 100\% HDPE and S1 composites.

\section{Degradation of the hybrid composites by soil burial}

The composite samples were buried in a flower pot soil. The moisture level of soil was kept at least $30 \%$. The samples were withdrawn carefully at an interval of 1 month period, washed with distilled water, dried at $80^{\circ} \mathrm{C}$ in an oven for $6 \mathrm{~h}$ and cooled in a desiccator. The degradation of the hybrid composites was determined by measuring the tensile strength.

\section{Result and discussion}

\section{Bulk density of the composites}

Figure 2 shows the effect of different fiber content on the bulk density of the composites. The figure indicates that the highest bulk density was found for 100\% HDPE. With the increase of fiber content from 5 to $25 \mathrm{wt} \%$ resulted in a decrease of bulk density of the composites. This type of trend in the bulk density with the increase of fiber content of the composites was also found for jute fiber reinforced LDPE composites [15].

\section{Water absorption of the composites}

The effect of different fiber content on water absorption of the composites is shown in Figure 3. It reveals that the quantity of water absorption of the composites increases with the increase of fiber content. Fibers absorb water rapidly due to its hydrophilic nature. The composites with more fiber showed more water absorption. Therefore, the S5 composite showed highest quantity of water absorption.

\section{Mechanical properties of the composites}

Mechanical properties such as tensile strength, elongation at break, tensile strength at break and yield strength of the composites are shown in Figures 4-7. Figure 4 shows the tensile strength of the hybrid composites at different fiber content. The tensile strength of $100 \%$ HDPE was found 20.16 MPa. The addition of $5 \mathrm{wt} \%$ fibers in HDPE (S1) increased the tensile strength than 100\% HDPE. The maximum tensile strength was $24.15 \mathrm{MPa}$ for S1 due to better fiber-matrix interfacial adhesion. But the tensile strength gradually decreased for the composites S2 to S5. This decreased trend in tensile strength of the composites may be attributed to low fiber - matrix adhesion between fiber and HDPE with the increase of fiber content in the composite.

The elongation at break of the hybrid composites for various wt $\%$ of fiber content is shown in Figure 5. 100\% HDPE presents the highest value of elongation at break. The elongation at break of the composites gradually reduced with the increase of fiber content from composites 
Khatun AM (2019) Physical, mechanical, thermal and morphological analysis of date palm mat (DPM) and palmyra palm fruit (PPF) fiber reinforced high density polyethylene hybrid composites

S1 to S5 because of brittle nature of fiber reinforced composites. The fibers present in the composites do not exhibit elasticity or flexibility to the composites. That's why the elongation at break reduces with the increase of fiber content.

Figure 6 shows the tensile strength at break of the hybrid composites at different fiber content. The maximum tensile strength at break value was found 22.07 MPa for S1 composites. Tensile strength at break reduced from composites S2 to S5 due to poor fiber-matrix adhesion.

Figure 7 shows the yield strength of the composites at different wt $\%$ of fiber content. The highest yield strength value was found $15.75 \mathrm{MPa}$ for S1. Yield strength value obtained for 100\% HDPE is lower than S1 composites. Yield strength reduced for composites S2 to S5.

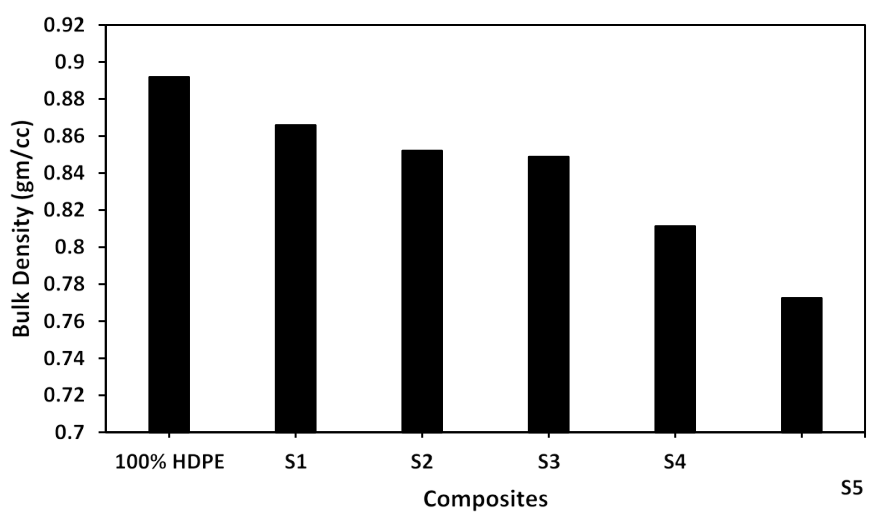

Figure 2. Bulk density of the composites at different fiber content

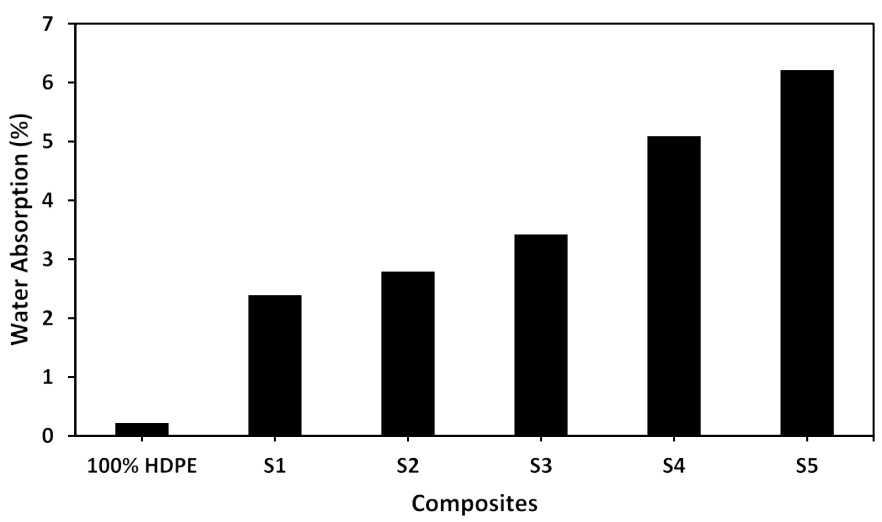

Figure 3. Water absorption of the composites at different fiber content

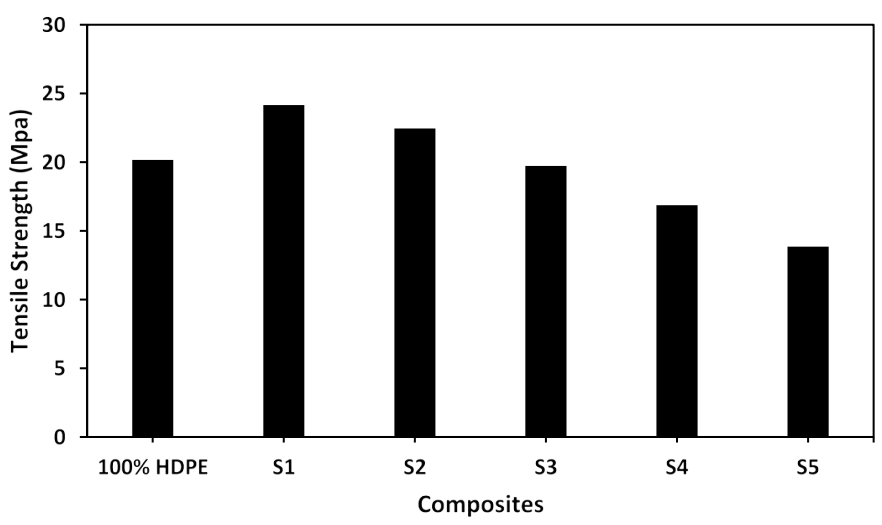

Figure 4. Tensile strength of the composites at different fiber content

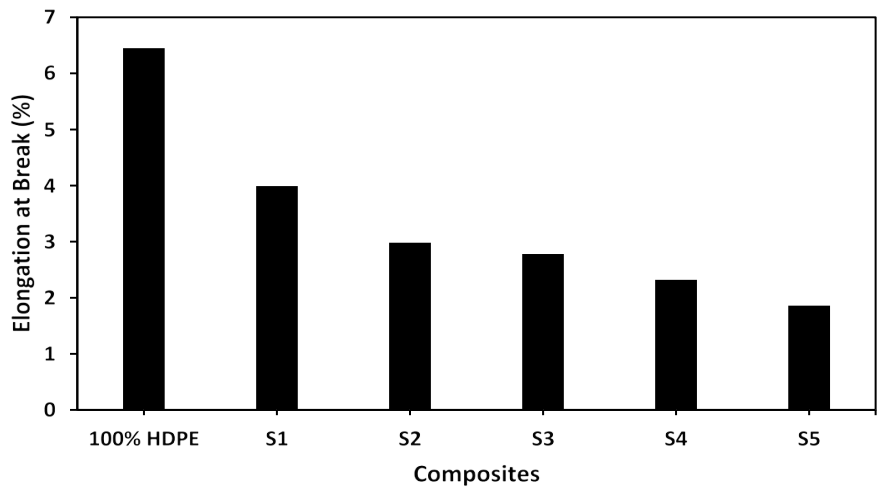

Figure 5. Elongation at break of the composites at different fiber content

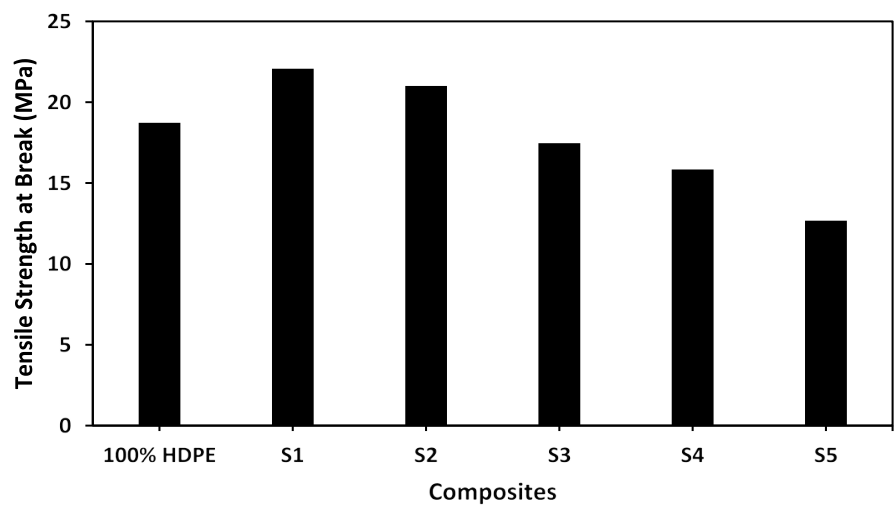

Figure 6. Tensile strength at break of the composites at different fiber content

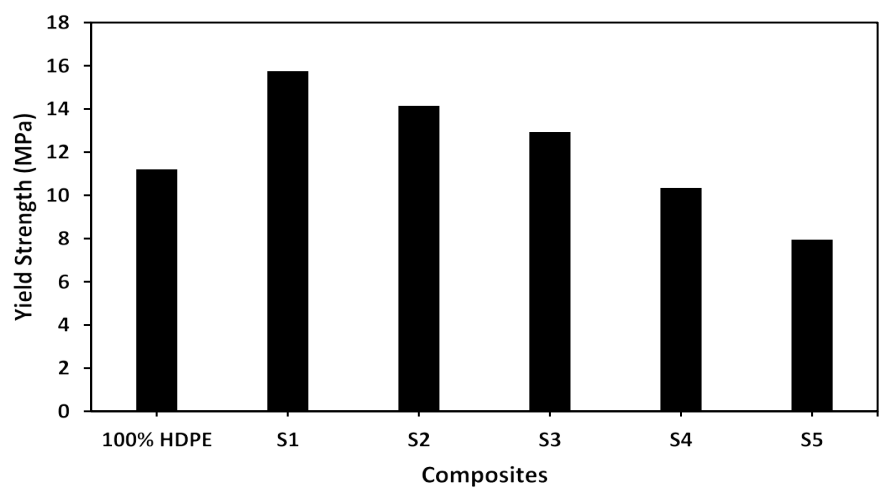

Figure 7. Yield strength of the composites at different fiber content

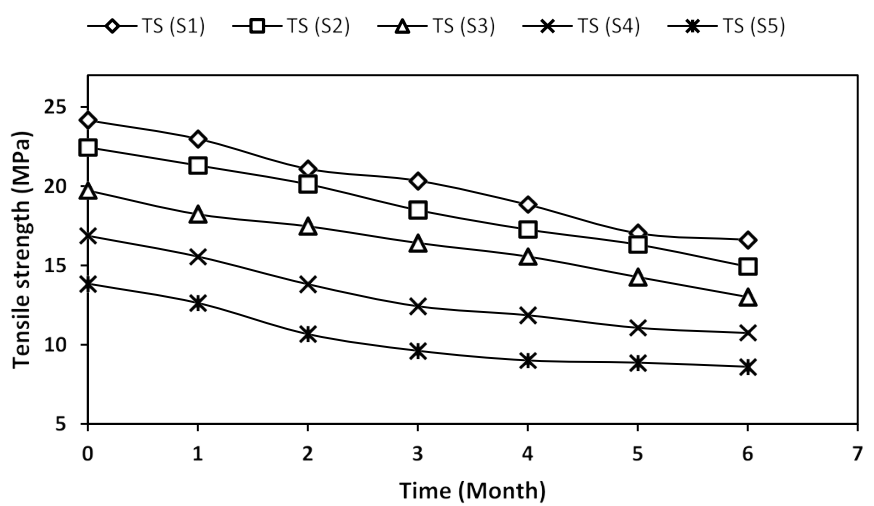

Figure 8. Degradation of tensile strength of the buried composite samples 
Khatun AM (2019) Physical, mechanical, thermal and morphological analysis of date palm mat (DPM) and palmyra palm fruit (PPF) fiber reinforced high density polyethylene hybrid composites

\section{Degradation of the hybrid composites by soil burial}

Degradation tests of the composites were carried out for up to six months. Figure 8 depicts the information about the degradation of the hybrid composites by soil burial. Degradation of the composites increased with time. The S1 composite lost $31.1 \%$ of tensile strength while S5 composite showed a loss of $37.8 \%$ of tensile strength. S1 composite showed more tensile strength than other composite samples. All composites express an increased degradation in the soil burial test. Moisture penetrates into the composites during soil burial tests. The fibers of composite surface and interface absorb water quickly because of hydrophilic nature and degrade slowly causing lower strength.

\section{Thermal properties analysis}

TGA and DSC were performed to examine the thermal stability of 100\% HDPE and S1 composites. The TGA and DSC curves are shown in the Figures 9 and 10. The TGA curve represents the percent mass of sample as a function of temperature. The Figure 9 shows that $100 \%$ HDPE composite started to degrade at $428.7^{\circ} \mathrm{C}$ with a mass change $97.68 \%$. In the case of Figure 10 the degradation of the composite started at $431.4^{\circ} \mathrm{C}$ and $88.91 \%$ mass change is accomplished at about $500^{\circ} \mathrm{C}$. The peaks of melting at 140.9 and $139.0^{\circ} \mathrm{C}$ were observed from the DSC curves of $100 \%$ HDPE and S1 composite. There was no considerable change in thermal properties of the composites with the addition of fibers.

\section{FTIR spectroscopy}

The FTIR spectra of 100\% HDPE and S5 composites were studied and given in Figures 11 and 12. The band around 2915, 1462 and 718 $\mathrm{cm}^{-1}$ are found for both 100\% HDPE and S5 composites. The FTIR spectra of S5 composite show five peaks at 3455, 1744, 1638,1258 and $1032 \mathrm{~cm}^{-1}$ and these are absent in 100\% HDPE. The peak at 2915, 1462 and $718 \mathrm{~cm}^{-1}$ corresponds to the $\mathrm{C}-\mathrm{H}$ stretching vibration, bending vibration of $-\mathrm{CH}_{2}$ and rocking vibration of $-\mathrm{CH}_{2}$ group respectively.
The absorption band at $3455,1744,1638,1258$ and 1032 indicate -OH stretching from cellulose, hemicellulose and lignin, $\mathrm{C}=\mathrm{O}$ stretching from the lignin and hemicellulose, $\mathrm{C}=\mathrm{C}$ stretching in aromatic, -COO vibration of acetyl groups in hemicellulose or aryl alkyl ether compounds existing in lignin and $\mathrm{C}=\mathrm{O}$ and $-\mathrm{OH}$ stretching vibrations of the polysaccharide in cellulose respectively.

\section{SEM analysis}

The scanning electron microscopy (SEM) analysis was carried out on the fracture surfaces of S1 and S5 composites and the images are shown in Figures 13 and 14. SEM micrographs represent that the S1 composite showed better interfacial bonding between HDPE matrix and fibers. On the other hand, S5 composite displayed poor fibermatrix adhesion between the matrix and the fiber. Gaps and a large extent of fiber pull-outs are observed for S5 composites and caused low mechanical properties.

\section{Conclusion}

DPM fiber and PPF fiber reinforced HDPE hybrid composites were fabricated by compression molding technique. It shows that the mechanical properties of hybrid composites improved at 5\% fiber content and then decreased. Therefore, better mechanical properties were observed for $5 \%$ optimum fiber content. SEM images also supported good fiber-matrix adhesion with 5\% fiber content. No considerable changes in thermal properties was found for hybrid and $100 \%$ HDPE composites. The degradation rate of the composite S1 (5\% DPM and PPF fiber content) was lower than other composites. These new hybrid composites may find applications in diverse field.

\section{Acknowledgement}

Bangladesh University Grant Commission is funded for this research. The authors are grateful to the University of Dhaka, UGC and BCSIR Laboratories, Dhaka for supporting the research work.

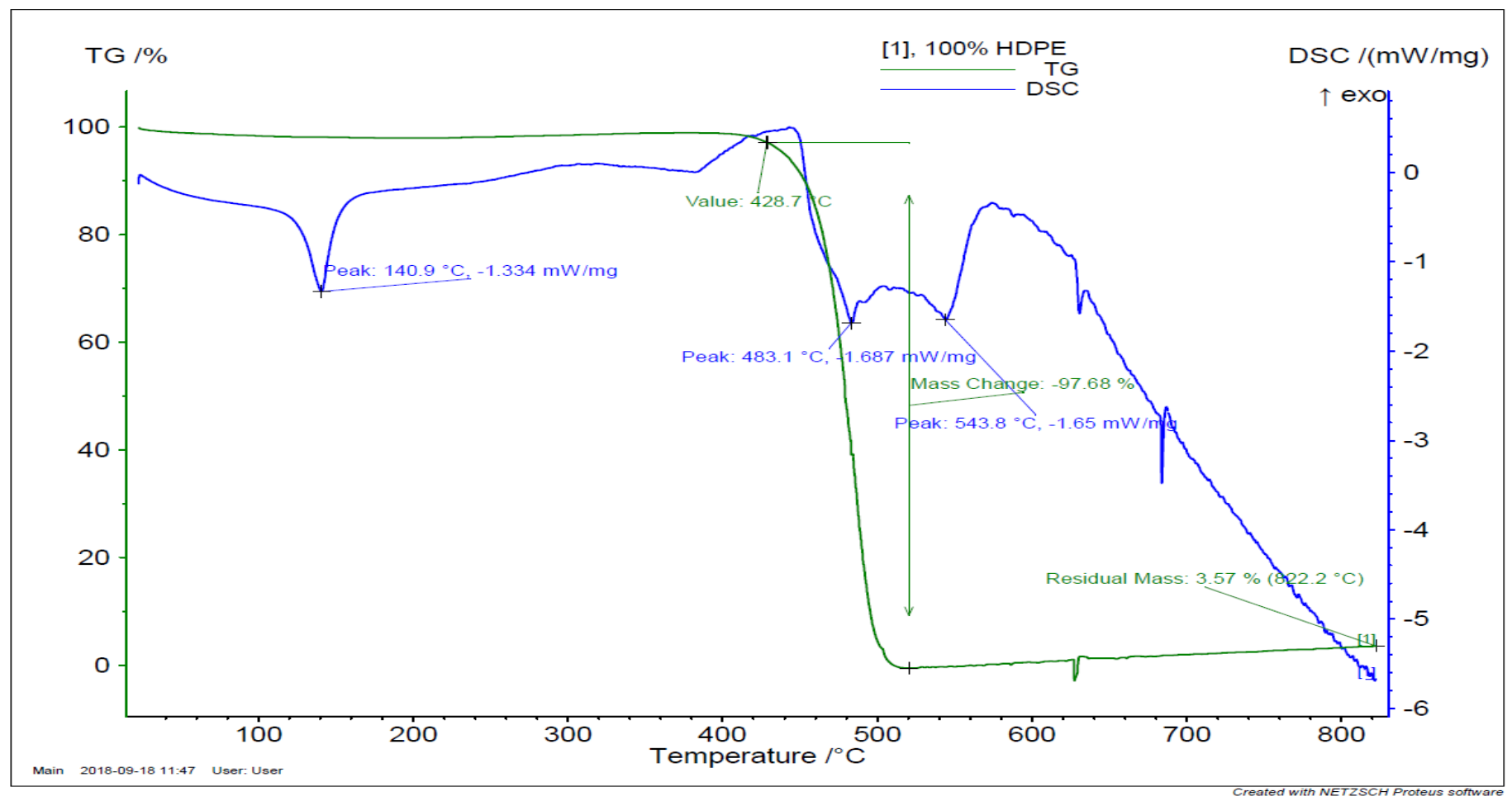

Figure 9. TGA and DSC of $100 \%$ HDPE 
Khatun AM (2019) Physical, mechanical, thermal and morphological analysis of date palm mat (DPM) and palmyra palm fruit (PPF) fiber reinforced high density polyethylene hybrid composites

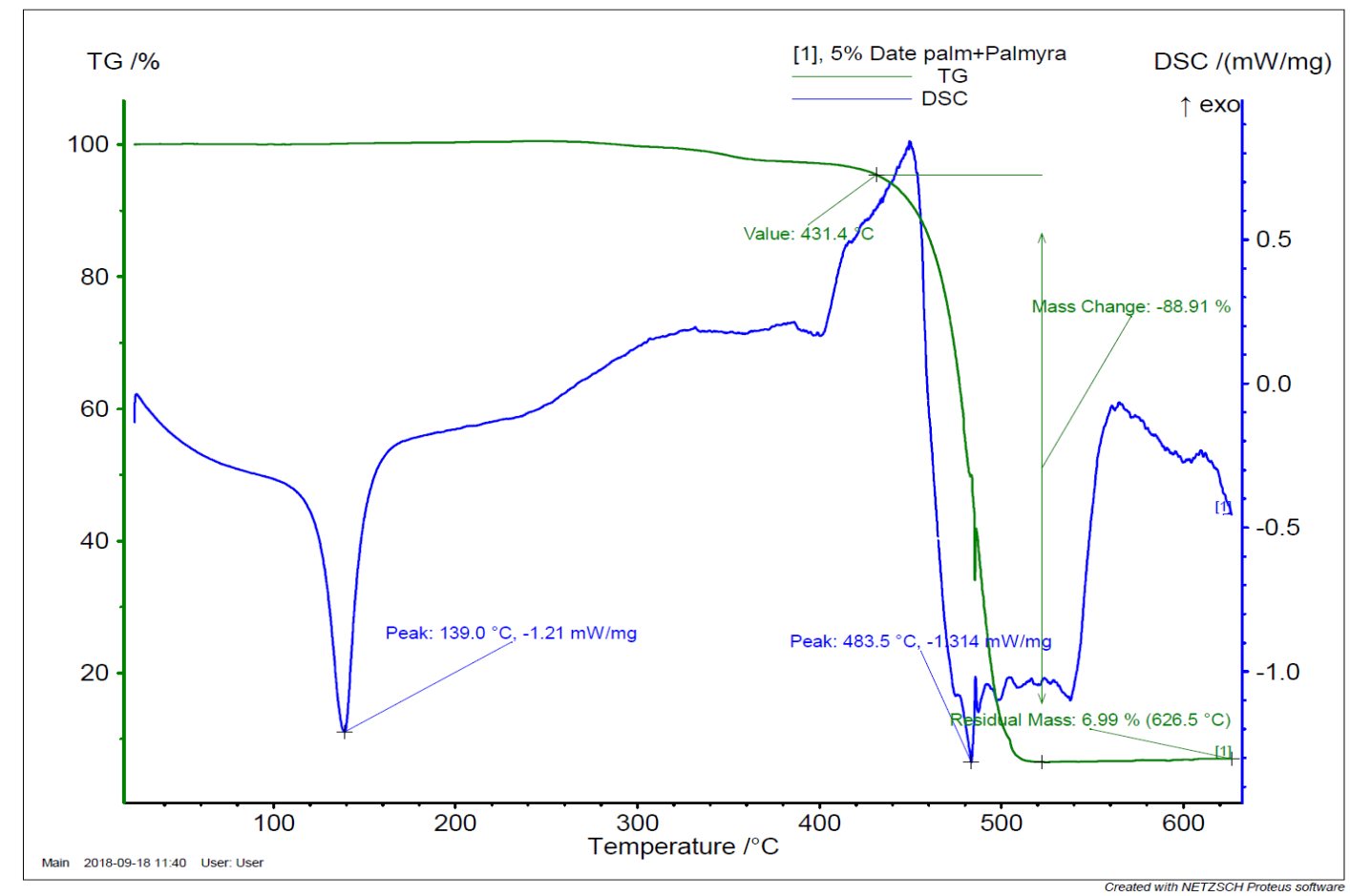

Figure 10. TGA and DSC of S1 composite

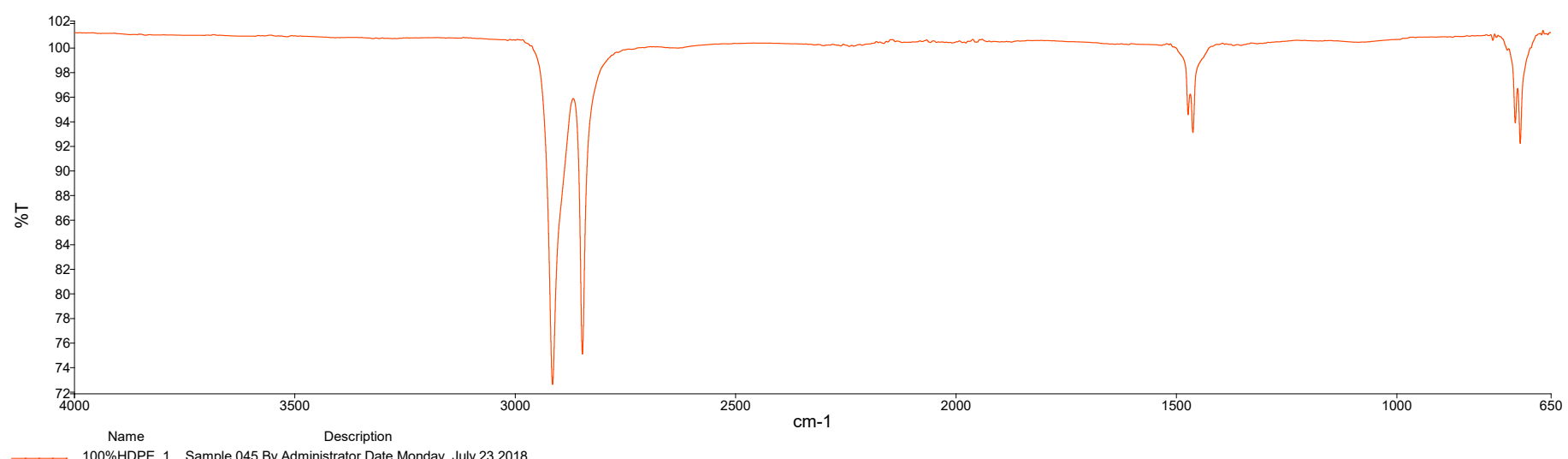

Figure 11. FTIR of $100 \%$ HDPE composite

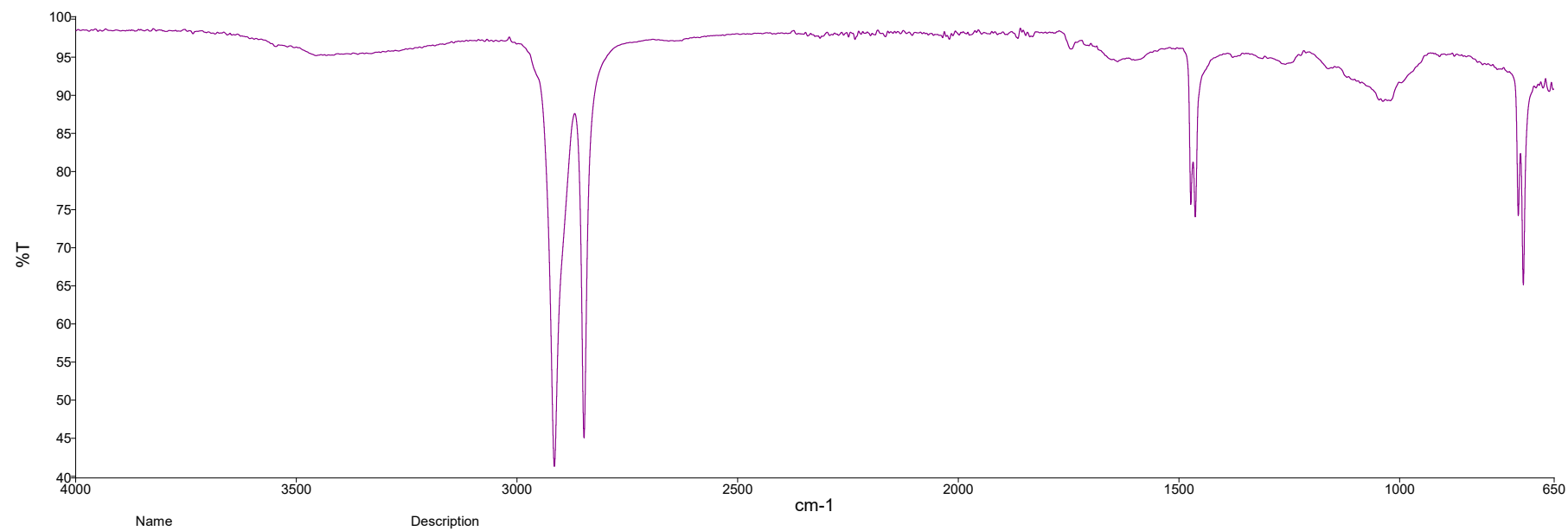

25\%PF + DPF + HDPE Sample 036 By Administrator Date Wednesday, November 062019

Figure 12. FTIR of S5 composite 
Khatun AM (2019) Physical, mechanical, thermal and morphological analysis of date palm mat (DPM) and palmyra palm fruit (PPF) fiber reinforced high density polyethylene hybrid composites

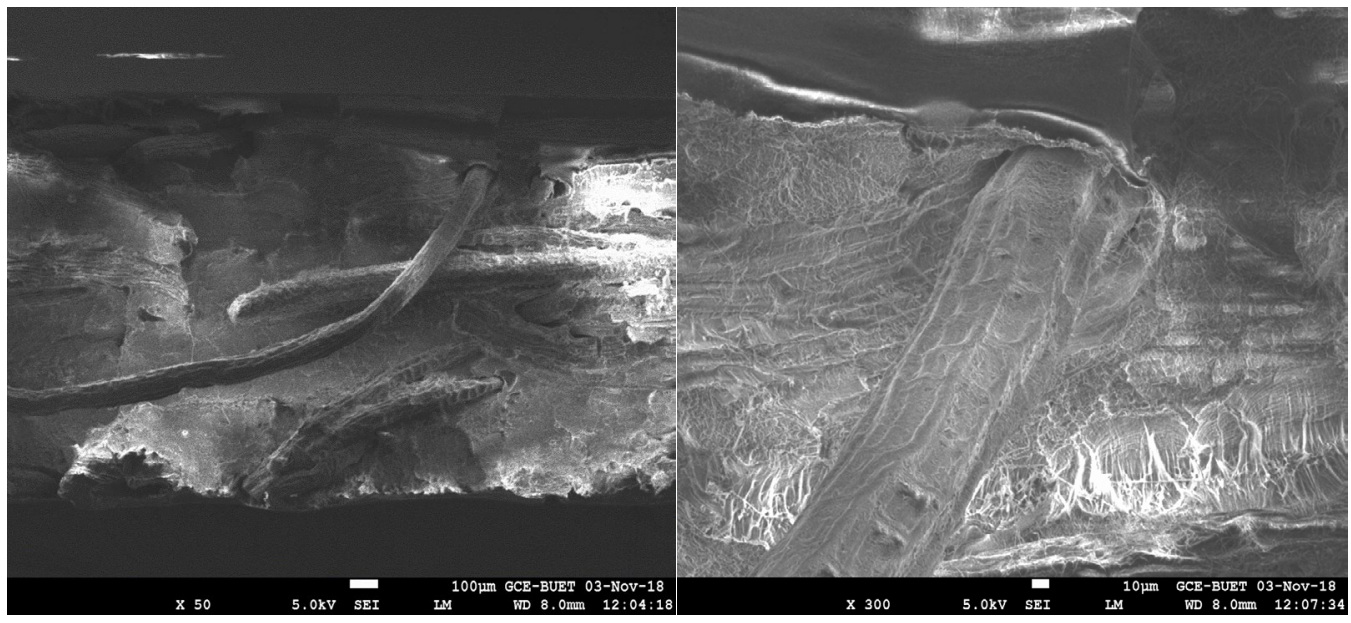

Figure 13. SEM images of $\mathrm{S} 1$ composite in different magnitude
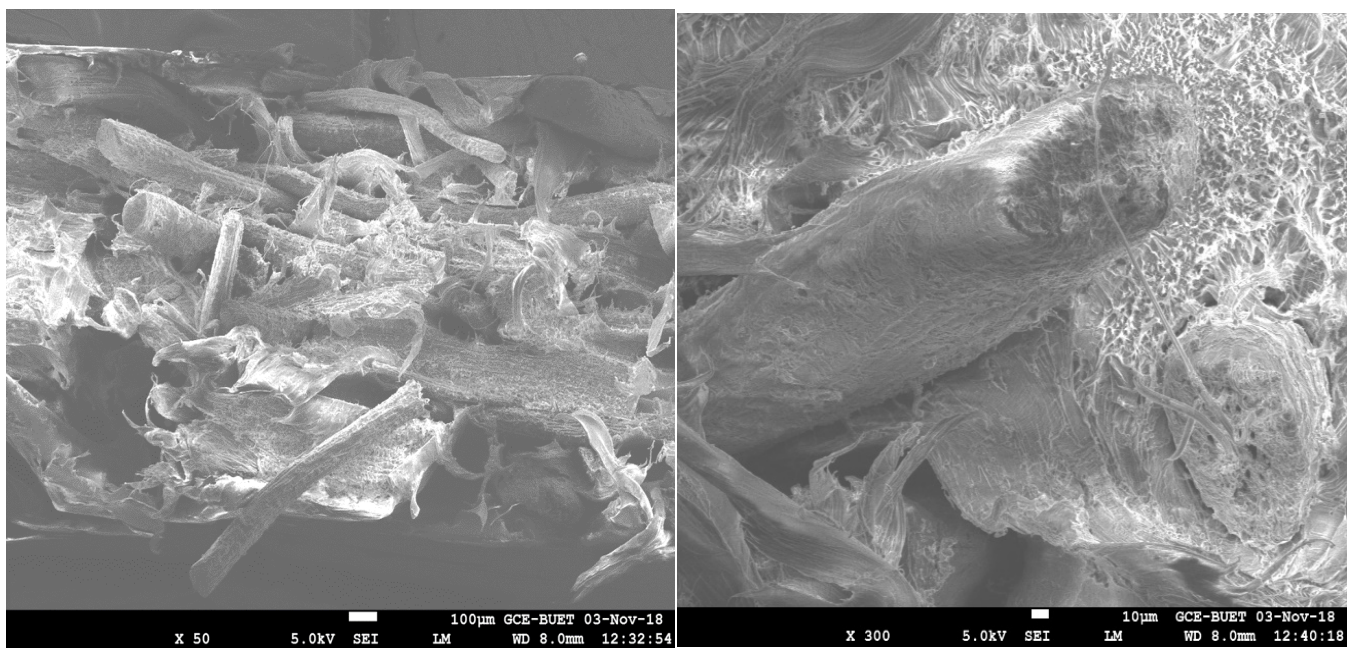

Figure 14. SEM images of S5 composite in different magnitude

\section{References}

1. Madhukiran J, Rao TV, Madhusudan S, Rao RU (2017) Evaluation of the mechanical properties on sisal-coir hybrid natural fiber composites. International Journal of Engineering Research and Development 13: 43-49.

2. Prasanna GV and Subbaiah KV (2013) Hardness, tensile properties and morphology of blend hybrid biocomposites. Scholarly Journal of Engineering Research 2: 21-29.

3. Tharaknath S, Selvakumar S, Purosthaman G (2014) Preparation and characterization of coir, luffa reinforced polypropylene composites. International Journal of Engineering Trends and Technology (IJETT) 16: 252-256.

4. Girisha C, Sanjeevamurthy A, Srinivas GR (2012) Sisal/Coconut coir natural fibers epoxy composites: water absorption and mechanical properties. International Journal of Engineering and Innovative Technology 2: 166-170.

5. Saba N, Tahir PM, Jawaid M (2014) A review on potentiality of nano filler/natural fiber filled polymer hybrid composites. Polymers 6: 2247-2273.

6. Appusamy AM, Eswaran P, Subramani M, Sadaiappan S (2018) Experimental studies on mechanical properties and characterization of parthenium short fibre reinforced polymer matrix composites. International Journal of Engineering and Advanced Technology 8: 94-97.

7. Li X, Tabil LG, Panigrahi S, Crerar WJ (2006) The influence of fiber content on properties of injection molded flax fiber-hdpe biocomposites. The Canadian Society for Bioengineering 6: 1-10.

8. Sudhir A, Madhukiran J, Srinivasaao RS, Madhusudan S (2014) Tensile and flexural properties of sisal/jute hybrid natural fiber composites. International Journal of Modern Engineering Research 4: 29-35.
9. Rao HR, Indraja Y, Bai GM (2014) Flexural properties and sem analysis of bamboo and glass fiber reinforced epoxy hybrid composites. Journal of Mechanical and Civil Engineering 11: 39-42.

10. Madhukiran J, Rao SS, Madhusudan S (2013) Fabrication and testing of natural fiber reinforced hybrid composites banana/pineapple. International Journal of Modern Engineering Research 3: 2239-2243.

11. Kumar NR, Prasad GR, Rao BR (2013) Investigation on mechanical properties of banana fiber glass reinforced hybrid thermoplastic composites. International Journal of Engineering Research \& Technology 2: 3701-3706.

12. Bhoopathi R, Ramesh M, Rajaprasanna R, Sasikala G, Deepa C (2017) Physica properties of glass-hemp-banana hybrid fiber reinforced polymer composites. Indian Journal of Science and Technology 10: 1-6.

13. Thiruchitrambalam M, Alavudeen A, Athijayamani A, Venkateshwaran N, Elaya Peruma A (2009) Improving mechanical properties of banana/kenaf polyester hybrid composites using sodium laulryl sulfate treatment. Materials Physics and Mechanics 8: 165-173.

14. Malathi B, Kumar PP (2018) Experimental investigation for evaluation of mechanical properties of rice husk and saw dust composites. international journal of trend in research and development 5: 6-10.

15. Jahan A, Rahman MM, Kabir H, Kabir MA, Ahmed F, et al. (2012) Comparative stud of physical and elastic properties of jute and glass fiber reinforced LDPE composites. International Journal of Scientific \& Technology Research 1: 68-72.

Copyright: (C)2019 Khatun AM. This is an open-access article distributed under the terms of the Creative Commons Attribution License, which permits unrestricted use, distribution, and reproduction in any medium, provided the original author and source are credited. 